\title{
Behçet Disease (BD) in two siblings affected with Familial Mediterranean Fever (FMF)
}

\author{
G Calcagno ${ }^{1}$, A Vitale ${ }^{1}$, F La Torre*1, N Decembrino ${ }^{1}$, C Fede ${ }^{1}$ and F Falcini ${ }^{2}$
}

Address: ${ }^{1}$ Deparment of Pediatrics, Pediatric Rheumatology, Messina, Italy and ${ }^{2}$ Department of Biomedicine, Division of Rheumatology, Transition Unit, Florence, Italy

* Corresponding author

from I5th Paediatric Rheumatology European Society (PreS) Congress

London, UK. 14-17 September 2008

Published: 15 September 2008

Pediatric Rheumatology 2008, 6(Suppl I):P263 doi:10.1 186/1546-0096-6-SI-P263

This abstract is available from: http://www.ped-rheum.com/content/6/SI/P263

(C) 2008 Calcagno et al; licensee BioMed Central Ltd.

\section{Background}

FMF is a genetic autoinflammatory disease, characterized by attacks of fever and painful serositis. Behcet's disease (BD) is an inflammatory disorder associated with vasculitis. Clinical manifestations of both diseases can mimic each other and the coexistence of both diseases in the same patient has been reported.

\section{Objective}

We observed 2 siblings (11 and 10 year-old) of Egyptian ancestry, with a single MEFV gene mutation and clinical symptoms of FMF and BD.

Their medical history of recurrent fever attacks started at the age of 14 and 6 months respectively. Fever was accompanied by cervical adenopathy, severe exudative pharyngitis, oral aphtosis, abdominal pain and diarrhoea, sometimes with bloody stools. At the age of 10 and 9 years, screening for autoinflammatory disorders was performed revealing a single mutated FMF gene (E148Q). Since they fulfilled Tel Hashomer criteria, colchicine was started.

Despite colchicines, both still presented shorter fever attacks, recurrent abdominal pain with diarrhoea, oral and genital aphtosis, mialgia and asthenia. Blood tests and abdominal ultrasound were normal. An ophthalmic evaluation showed panuveitis in both.
Recurrence of oral and genital ulcers, abdominal pain and uveitis strongly suggested the diagnosis of $\mathrm{BD}$ even though HLA B51 was not detected.

\section{Conclusion}

Diagnosis of FMF and BD is clinical. Our patients fulfilled Tel Hashomer criteria for FMF and international diagnostic criteria of $\mathrm{BD}$. The increase of colchicine induced a sustained clinical improvement. Physicians have to be aware of the possible association of both conditions.

\section{References}

I. Touitou I, et al.: MEFV mutations in Behçet's disease. Hum Mutat 2000, I6(3):27I-2. 